\title{
Novel switching technique for five leg inverter in dual motor control
}

\author{
Jayaprakash Sabarad ${ }^{1}$, G.H. Kulkarni ${ }^{2}$ \\ ${ }^{1}$ Department of Electrical Engineering, Visvesvaraya Technological University, India \\ ${ }^{2}$ Department of Electrical Engineering, Jain College of Engineering, India
}

\begin{tabular}{|c|c|}
\hline Article Info & ABSTRACT \\
\hline Article history: & This work presents a novel switching technique for five leg inverter in dual \\
\hline Received Dec 5, 2019 & motor control. As the technology advances in industry, requirements in \\
\hline Revised Mar 6, 2020 & In conventional method, the six legs are used in 2 - three phase Voltage \\
\hline Accepted Mar 20, 2020 & $\begin{array}{l}\text { Source Inverters (VSI) to control } 2 \text { motors. This proposed technique will } \\
\text { give the improved performance of speed control for dual motor control using }\end{array}$ \\
\hline Keywords: & $\begin{array}{l}\text { Five Leg Inverter (FLI). New proposed method suggests to use 5-1nverter } \\
\text { legs instead of 6-inverter legs to control } 2 \text { induction motors. New Switching }\end{array}$ \\
\hline $\mathrm{CM}$ & technique proposed in FLI system is designed in effective way that improved \\
\hline DTC & performance and Total Harmonic Distortion of $\sim 23 \%$ achieved. The load \\
\hline FLI & sharing on common leg is called Common Mode $(\mathrm{CM})$ of operation. In this \\
\hline SVPWM & modulation (SVPWM) and Direct Torque Control (DTC) in FLI Technology. \\
\hline VSI & $\begin{array}{l}\text { With this new method smooth speed regulation is achieved when load torque } \\
\text { is changed. THD\% for CM-FLI is reduced when compared with convetional } \\
\text { FLI technique. The new Switching technique is controlled in effective way } \\
\text { that the common leg is not overloaded and able to drive both the induction } \\
\text { motors independently at required speeds. Proposed switching technique } \\
\text { verified at different operating speeds with No load and rated torque. } \\
\text { Simulation results computed using MATLAB/SIMULINK Software. }\end{array}$ \\
\hline
\end{tabular}

Copyright $(2020$ Institute of Advanced Engineering and Science. All rights reserved.

\section{Corresponding Author:}

Jayaprakash Sabarad,

Research Scholar, Department of Electrical Engineering,

VTU RRC Belagavi, PO\#590018 Karnataka, Belagavi, India.

Email: jpsabarad@gmail.com

\section{INTRODUCTION}

Present trend in industries are looking for the advanced control methodology with precise speed control. The industries looking for minimising the cost with improved performance in drive control system. In this regard the proposed work is carried out to reduce cost and to give improved performance in the field of 3-phase Induction Motor (IM) control. As the number of inverter switching devices increases more, then it leads to complex control design $[1,2]$ and also affects reliability of the system. The proposed solution helps in reducing the number of switching elements, thus reduces the cost, and size of the system [3, 4].

The proposed solution is having the 5-legs inverters instead of conventional 6-legs inverter for dual motor control. The main aim of this five leg is to have reduced switching elements from 12 to 10 [5]. The new technology uses only 10 switching elements with switching combination is up to 25. Closed loop control is done by interfacing FLI -SVPWM with DTC of induction motor [6, 7].

The main drawback of those conventional methodologies are, in case of dual voltage modulation (DVM) two consecutive switching periods are applied for each motor, due to this DC voltage restricted to half. In case of modulation block method (MBM) applied reference voltage shall be known prior to 
application. Whereas in inversion table method (IVM) method bigger look up table need to be designed and difficult to be implemented on digital processors [8-10].

In this novel design of switching technique in FLI is common mode of operation. This common leg shares load of each motor and also supply voltage to both motors. Hence it is important to have the optimal switching technique to be used in such a manner that the common leg does not get overloaded. The novel switching technique is called CM-FLI technology gives improved performance of speed control and is explained in detail in below section.

\section{CONTROL TECHNIQUE AND SWITCHING METHODOLOGY}

\subsection{Mathematical equations for DTC of induction motor}

In Conventional DTC the stator flux and torque are regulated within limited hysteresis bands and which in turn switch the VSI to apply appropriate stator voltage. In conventional method the flux and torque errors are directly used to generate the switching pulses to VSI [11-13]. An improved DTC is proposed here is reference stator voltage vectors are produced by torque and flux errors as given in below (1) to (12), which in turn modulated by means of SVPWM technique $[14,15]$. The field component is aligned to d-axis and torque component is aligned to q-axis and both are orthogonal to each other.

The (1) to (6) gives the motor stator voltage from stator reference frame. The flux and torque with respect to load torque and inertia is given as below.

$$
\begin{aligned}
& \mathrm{V}_{\mathrm{s}}^{\mathrm{g}}=\mathrm{i}_{\mathrm{s}}^{\mathrm{g}} * \mathrm{R}_{\mathrm{s}}+\mathrm{j} \mathrm{w}_{\mathrm{g}} * \Phi_{\mathrm{s}}^{\mathrm{g}}+\mathrm{p} * \Phi_{\mathrm{s}}^{\mathrm{g}} \\
& 0=\mathrm{i}_{\mathrm{r}}^{\mathrm{g}} * \mathrm{R}_{\mathrm{r}}+\mathrm{j}\left(\mathrm{w}_{\mathrm{g}}-\mathrm{w}_{\mathrm{r}}\right) * \Phi_{\mathrm{r}}^{\mathrm{g}}+\mathrm{p} * \Phi_{\mathrm{r}}^{\mathrm{g}} \\
& \Phi_{\mathrm{s}}^{\mathrm{g}}=\mathrm{L}_{\mathrm{s}} * \mathrm{i}_{\mathrm{s}}^{\mathrm{g}}+\mathrm{L}_{\mathrm{m}} * \mathrm{i}_{\mathrm{r}}^{\mathrm{g}} \\
& \Phi_{\mathrm{r}}^{\mathrm{g}}=\mathrm{L}_{\mathrm{r}} * \mathrm{i}_{\mathrm{r}}^{\mathrm{g}}+\mathrm{L}_{\mathrm{m}} * \mathrm{i}_{\mathrm{r}}^{\mathrm{g}} \\
& \mathrm{T}_{\mathrm{e}}-\mathrm{T}_{\mathrm{L}}=\mathrm{J} * \mathrm{p} * \mathrm{w}_{\mathrm{r}}+\mathrm{B}_{\mathrm{m}} * \mathrm{w}_{\mathrm{r}} \\
& \mathrm{T}_{\mathrm{e}}=3 * \frac{\mathrm{p}}{4}\left(\Phi_{\mathrm{sd}}^{\mathrm{g}} * \mathrm{i}_{\mathrm{sq}}^{\mathrm{g}}-\Phi_{\mathrm{sq}}^{\mathrm{g}} * \mathrm{i}_{\mathrm{sd}}^{\mathrm{g}}\right)
\end{aligned}
$$

Where,

$\mathrm{V}_{\mathrm{s}}$ is stator applied voltage. $\mathrm{R}_{\mathrm{r}}$ and $\mathrm{R}_{\mathrm{s}}$ are rotor and stator resistances. $\Phi_{\text {sd }}, \Phi_{\text {sq }}$ are stator flux linkages. $\mathrm{i}_{\mathrm{s}}, \mathrm{i}_{\mathrm{q}}$ are stator and rotor current. Mutual inductance is $\mathrm{L}_{\mathrm{m}}$.

$\mathrm{L}_{\mathrm{s}}, \mathrm{L}_{\mathrm{r}}$ are stator and rotor self-inductances. $\mathrm{T}_{\mathrm{L}}, \mathrm{T}_{\mathrm{e}}$ are load torque and electromagnetic torque and, $\mathrm{w}_{\mathrm{g}}, \mathrm{w}_{\mathrm{r}}$ are reference field and rotor speed. Model equations can be represented in stationary stator reference frames to estimate the Torque and flux linkages as below. In stationary reference frame $\alpha$ is magnetic linkages of stator coil resistance $\mathrm{R}$.

The estimation of stator flux as,

$$
\Phi_{\mathrm{s}}^{\alpha}=\int\left(\mathrm{V}_{\mathrm{s}}^{\alpha}-\mathrm{i}_{\mathrm{s}}^{\alpha} * \mathrm{R}_{\mathrm{s}}\right) \mathrm{dt}
$$

Magnitude of stator flux as,

$$
\left.\Phi_{\mathrm{s}}^{*}=\left|\Phi_{\mathrm{s}}^{\alpha}\right|=\sqrt{(} \Phi_{\mathrm{sd}}^{\alpha}+\Phi_{\mathrm{sq}}^{\alpha}\right)
$$

Estimation of position vector as,

$$
\theta_{\mathrm{e}}=\tan ^{-1}\left\{\frac{\Phi_{\mathrm{sq}}^{\alpha}}{\Phi_{\mathrm{sd}}^{\alpha}}\right\}
$$

Estimation of motor torque as,

$$
\mathrm{T}_{\mathrm{e}}=\frac{3 \mathrm{P}}{4}\left(\Phi_{\mathrm{sd}}^{\alpha} * \mathrm{i}_{\mathrm{sq}}^{\alpha}-\Phi_{\mathrm{sq}}^{\alpha} * \mathrm{i}_{\mathrm{sd}}^{\alpha}\right)
$$

Where, Te is the reference electromagnetic torque estimated from the motor. 


$$
\begin{aligned}
& \Delta \mathrm{T}_{\mathrm{e}}=\mathrm{T}_{\mathrm{e}}-\mathrm{T}_{\mathrm{e}}^{*} \\
& \Delta \Phi_{\mathrm{e}}=\Phi_{\mathrm{e}}-\Phi_{\mathrm{s}}^{*}
\end{aligned}
$$

The flux error and torque error are used to produce the decoupled stator reference vector by means of PI regulator. With the above information the reference voltage then be converted in to voltage vector by means of stator co-ordinates reference co-ordinate transformation. DTC technique used in variable speed control of asynchronous motor fed by VSI. Using Clark transformation, measured 3-phase stator currents and voltages are then converted to 2-phase co-ordinates $(\alpha, \beta)$. The 2-phase co-ordinates then converted to d, q co-ordinates [16-18].

\subsection{SVPWM technique}

The 2-level SVPWM technique is applied to control the inverter switching pulses. This method has proven better than the other PWM techniques like SPWM [19, 20]. This SVPWM technique is used for precise speed control and optimal switching technique. Due to this the reduction in the switching harmonics and utilization of higher DC bus volts. The DTC and SVPWM combined to achieve the precise torque control [21-23].

In the first sector $V_{s}$ is voltage vector, which is reference voltage as shown in the Figure 1. The voltage is selected for two zero vectors and active voltage vectors, $V_{7}(000)$ or $V_{8}(111), V_{2}(110)$, $V_{1}(100)$ respectively. Vectors are selected in anticlockwise direction. Reference vector can be anywhere in the above six sectors. Each time sector selection and timing of the reference selection is computed [24, 25].

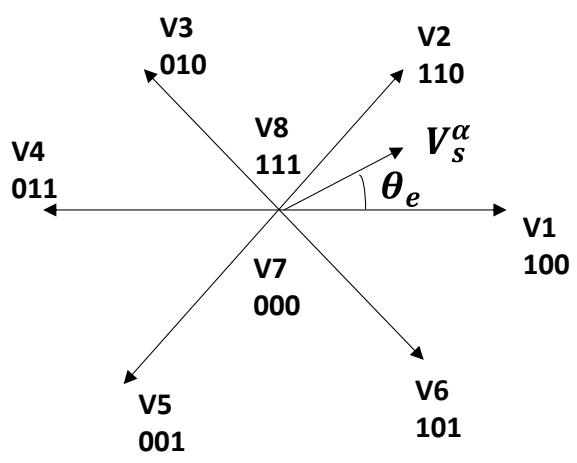

Figure 1. Space vector representation for voltage vector

The switching of inverter is made such that, zero state space vectors $V_{7}$ or $V_{8}$ for $T_{0}$ period, space vector $V_{1}$ for $T_{1}$ period and space vector $V_{2}$ for $T_{2}$ period. Let $D_{0}, D_{1}, D_{2}$ represents duty cycles of $V_{7} / V_{8}$, $\mathrm{V}_{1}, \mathrm{~V}_{2}$ and respectively. The relationship between timing $\mathrm{T}_{0}, \mathrm{~T}_{1}, \mathrm{~T}_{2}, \mathrm{~T}_{\mathrm{S}}$ and voltage $\mathrm{V}_{\mathrm{S}}$ is given by (13), (14), (15), (16) and (17).

$$
\begin{aligned}
& \mathrm{T}_{1} \mathrm{~V}_{1}+\mathrm{T}_{2} \mathrm{~V}_{2}=\mathrm{T}_{\mathrm{S}} \mathrm{V}_{\mathrm{S}}=\mathrm{MV}_{\mathrm{dc}} \\
& \mathrm{T}_{1}+\mathrm{T}_{2}+\mathrm{T}_{0}=\mathrm{T}_{\mathrm{S}}
\end{aligned}
$$

Where, $\mathrm{M}$ is Mdoulation index, $\mathrm{T}_{0}, \mathrm{~T}_{1}$ and $\mathrm{T}_{2}$ are calculated as below,

$$
\begin{aligned}
& \mathrm{T}_{1}=\mathrm{T}_{\mathrm{S}} * \mathrm{M} * \sin \left(\frac{\pi}{3}-\theta\right) \\
& \mathrm{T}_{2}=\mathrm{T}_{\mathrm{S}} * \mathrm{M} * \sin (\theta) \\
& \mathrm{T}_{0}=\mathrm{T}_{\mathrm{S}}-\mathrm{T}_{1}-\mathrm{T}_{2}
\end{aligned}
$$

the duty cycles for the voltage vectors are given by (18), 


$$
\mathrm{D}_{1}=\mathrm{T}_{1} / \mathrm{T}_{\mathrm{S}}, \mathrm{D}_{2}=\mathrm{T}_{2} / \mathrm{T}_{\mathrm{S}}
$$

Defining the modulation index by (19),

$$
\mathrm{M}=\left|\mathrm{V}_{\mathrm{s}} / \mathrm{V}_{\mathrm{DC}}\right|
$$

$T_{S}$ is switching period, and $\theta$ is angle bewteen stator volatge $V_{s}$ and common null vectors $V_{n}$.

\section{COMMON MODE-FIVE LEG INVERTER (CM-FLI) USING SVPWM}

The switching techniques for the 3-leg inverter is common in many applications. In FLI -VSI method the critical part is computing common mode voltage $V_{C}$, which shares common leg between two inverters. Common leg voltage $V_{C}$ shares the voltage between two motors. The reference signal for both the inverters are computed in such a way that reference signals does not include the zero sequence component.

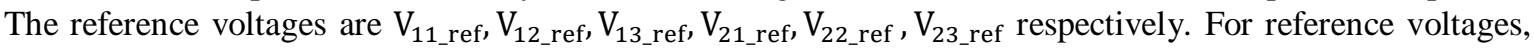
the zero sequence voltages are getting added to reduce lower currents harmonics and also to increase the available modulation index given in (19) to (24).

$$
\begin{aligned}
& \mathrm{V}_{11}=\left(\frac{\mathrm{V}_{\mathrm{dc}}}{2} * \mathrm{M}\right) * \sin \mathrm{wt}+\mathrm{V}_{\text {Zero }} \\
& \mathrm{V}_{12}=\left(\frac{\mathrm{V}_{\mathrm{dc}}}{2} * \mathrm{M}\right) * \sin (\mathrm{wt}+2 \pi / 3)+\mathrm{V}_{\text {Zero }} \\
& \mathrm{V}_{13}=\left(\frac{\mathrm{V}_{\mathrm{dc}}}{2} * \mathrm{M}\right) * \sin (\mathrm{wt}-2 \pi / 3)+\mathrm{V}_{\text {Zero }}
\end{aligned}
$$

Similarly for the second inverter machine the reference signal is computed by,

$$
\begin{aligned}
& \mathrm{V}_{21}=\left(\frac{\mathrm{V}_{\mathrm{dc}}}{2} * \mathrm{M}\right) * \sin \mathrm{wt}+\mathrm{V}_{\text {Zero }} \\
& \mathrm{V}_{22}=\left(\frac{\mathrm{V}_{\mathrm{dc}}}{2} * \mathrm{M}\right) * \sin (\mathrm{wt}+2 \pi / 3)+\mathrm{V}_{\text {Zero }} \\
& \mathrm{V}_{23}=\left(\frac{\mathrm{V}_{\mathrm{dc}}}{2} * \mathrm{M}\right) * \sin (\mathrm{wt}-2 \pi / 3)+\mathrm{V}_{\text {Zero }}
\end{aligned}
$$

Where,

$\mathrm{V}_{11}, \mathrm{~V}_{12}, \mathrm{~V}_{13}, \mathrm{~V}_{21}, \mathrm{~V}_{22}$ and $\mathrm{V}_{23}$ are voltage input signals fed to SVPWM technique. Now the six output voltages have to be converted to five called five leg inverter output. The main switching technique is called common mode technique.

In this common mode technique, inverter output voltages are only five and one common leg is present between the two inverters. The load on the common leg inverter will be more, so in order to avoid the extra load, the switching technique used here is combination of SVPWM and also common mode techniques. This common leg to share the load current and which results in little more current flows in common leg than the other four legs. A novel switching technique of five leg VSI is shown in Figure 2. The common mode of operation of 2 three-phase modulators are added in such a manner, that number of switching signals gets reduced from six to five as shown in Figure 2. Where $S_{11}, S_{12}, S_{13}, S_{21}, S_{22}$ and $S_{23}$ are the switching pulses for the 5-leg inverter. SVPWM and CM mode combined to achieve the right inverter pulse to FLI. The fiveleg VSI with common leg mode of operation for dual three phase induction motor is shown in Figure 3. From Figure 3, complete connection of dual motors in FLI system is shown and common leg C is connected to both motors. The switching technique is designed in such a way that the current limit is maintained and is also called common mode voltage. 


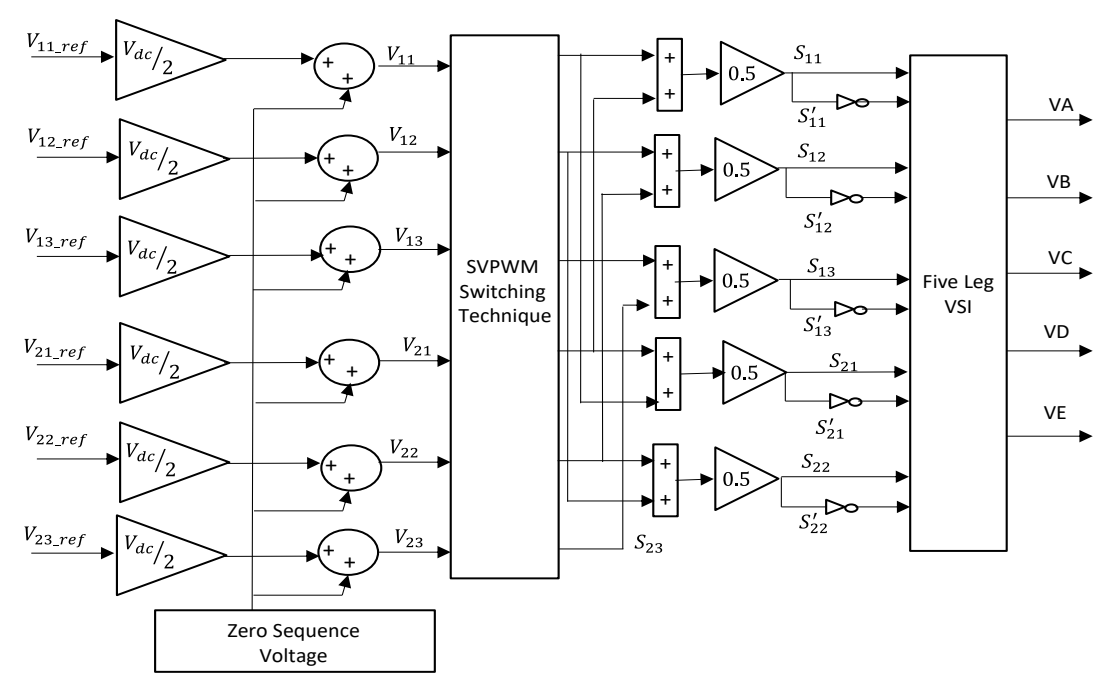

Figure 2. Novel switching technique of CM-FLI using SVPWM

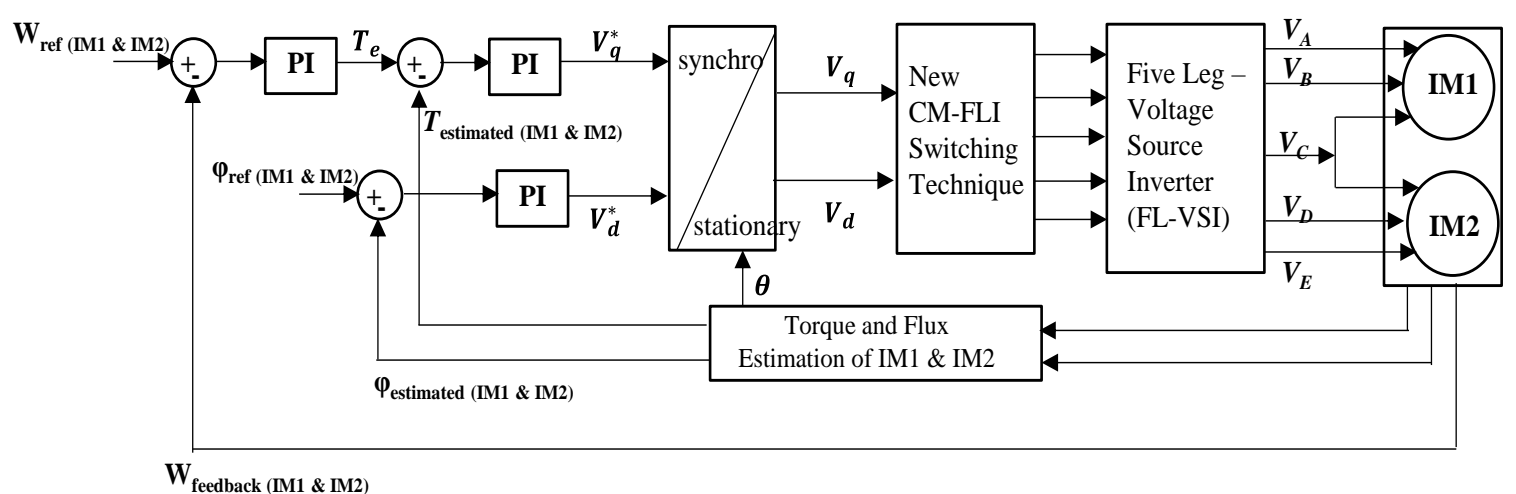

Figure 3. Complete block diagram of Five-leg VSI - CM of operation for dual motor

\section{SIMULATION RESULTS AND DISCUSSIONS}

Modelling and Simulation plays a very important role in the field of drives control. The effectiveness of the five leg inverter techniques proved by running various simulation results are computed using Matlab/Simulink. Induction motor ratings are given as in Table 1.

Table 1. Induction motor ratings

\begin{tabular}{cc}
\hline Induction Motors IM1 Ratings: & Induction Motors IM2 Ratings: \\
\hline 7.5KW (10HP), 50Hz, 400V, 1500rpm. & $7.5 \mathrm{KW}(10 \mathrm{HP}), 50 \mathrm{~Hz}, 400 \mathrm{~V}, 1500 \mathrm{rpm}$ \\
\hline
\end{tabular}

The results are obtained and proved from the novel switching SVPWM based fed to FLI system for dual motor speed control results found satisfactorily. Both the motors are controlled independently and verified at rated load torque at different motor speeds. Both motor running at different speed verified and shown in output waveforms. The output waveforms from Figure 4 to Figure 9 shows the independent operation of dual induction motors.

Figure 4, shows the motor phase voltages and Figure 5, shows the motor line voltages. In Figure 6, both motors are commanded to operate at $1400 \mathrm{rpm}$ and $1440 \mathrm{rpm}$ respectively. The independent control of dual motor speeds are shown in Figure 7. Where initially both motors are commanded to run at the same speed and after that both motors operating at different speed. The proposed novel CM-FLI switching technique shows the improved performance of the system with respect to existing switching techniques as compared in Table 2. FLI-VSI Induction Motor Output Waveforms at Rated Load Torque. 


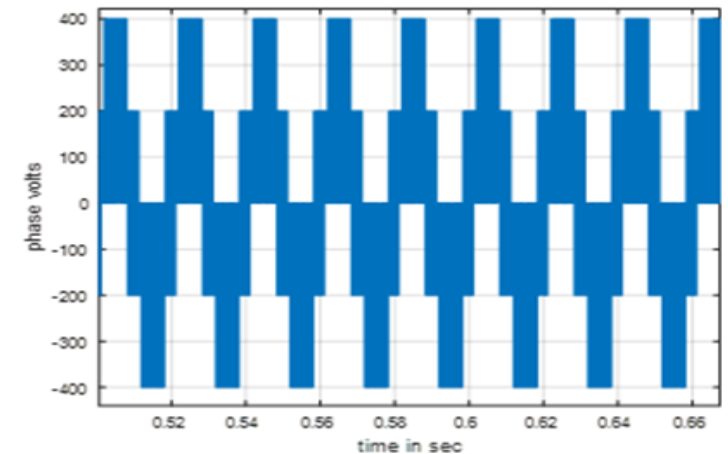

Figure 4. Five leg inverter output phase volts (volt)

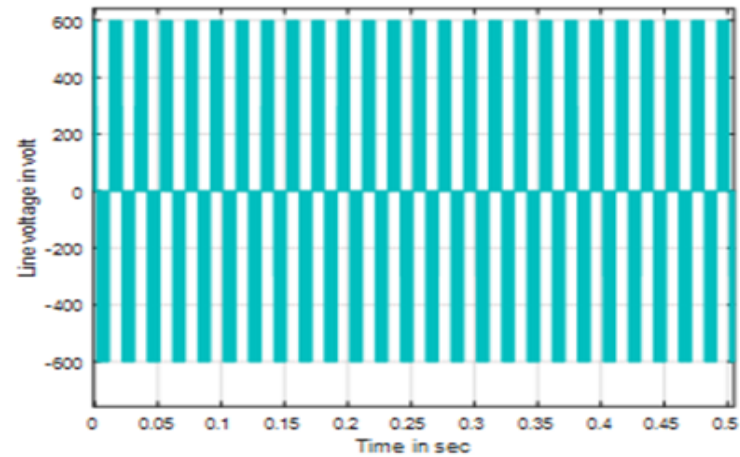

Figure 5. Five leg inverter output line volts (volt)

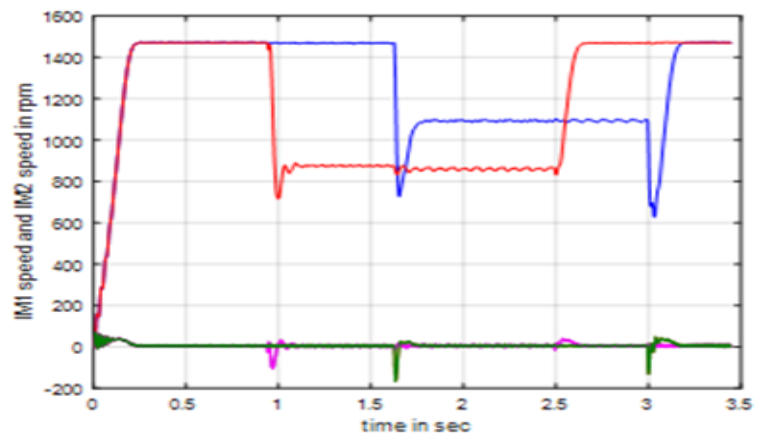

Figure 7. FLI-IM 1 and IM2 independent speeds $(\mathrm{rpm})$ and torque $(\mathrm{N}-\mathrm{m})$ control operation

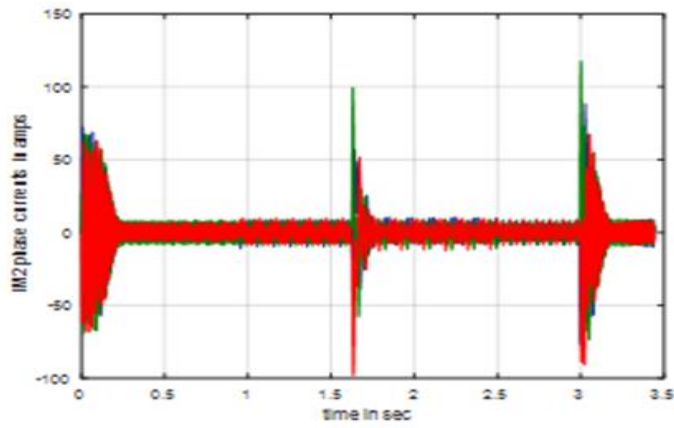

Figure 9. FLI-IM2 phase currents (amps) based
Figure 7 of independent speed
Figure 9. FLI-IM2 phase currents (amps) based
Figure 7 of independent speed
Figure 8. FLI-IM 1 phase currents (amps) based on Figure 7 of independent speed

From Figure 7, IM1 speed commanded to operate at 850rpm and IM2 speed commanded to operate 1100rpm, during this period the IM1 and IM2 motor phase currents are shown in Figure 8 and Figure 9 respectively. From this simulation results, independent speed control of dual motor operation is achieved at different operating speed.

\subsection{THD comparison}

From Table 2, New Swicthing technique CM-FLI holds good from the motor thermal stand point as THD is lower than the conventional PWM technique. Total Harmonic Distortion (THD) is compared with standard single motor Vs FLI techniques. Thus the New switching technique (CM-FLI) holds good from operating stand point. This proposed technique will give the improved performance of $\sim 23 \%$ for dual motor control using Five Leg Inverter (FLI). 


\begin{tabular}{|c|c|c|c|}
\hline & $\begin{array}{c}\text { Three Leg Inverter, Single Induction } \\
\text { Motor (SPWM) }\end{array}$ & $\begin{array}{c}\text { Five Leg Inverter, } \\
\text { Coventional SPWM with } \\
\text { Dual Motor }\end{array}$ & $\begin{array}{c}\text { Five Leg Inverter, } \\
\text { New PWM (CM-FLI) with } \\
\text { Dual Motor }\end{array}$ \\
\hline Output Phase Current THD \% & $11.59 \%$ & $22.03 \%$ & $14.31 \%$ \\
\hline
\end{tabular}

\section{CONCLUSIONS}

From the above results, novel switching technique of CM-FLI using SVPWM plays an important role in switching the five leg inverter. This new CM-FLI switching technique uses only 10 switching elements with switching combination is up to 25 . From the simulation results the proposed technique will give the improved performance of $\sim 23 \%$ for dual motor control using Five Leg Inverter (FLI). The THD \% of the New CM-FLI system reduced to $14.31 \%$ from conventional $22.03 \%$ for the Motor phase currents. The direct torque control for dual induction motor controlled independently with different load torque at different speed of operation. Switching methodology is verified for no rated load torque operation. The common DC link voltage is applied to both motors are same. It is verified that the common leg is able to share the both motor load current at different operating speeds. From this CM-FLI using SVPWM system is found to be most cost productive, reduced complex control algorithm and used in precise speed control of dual three phase induction motors independently. This work can be extended for different control methodology for the induction motor control.

\section{REFERENCES}

[1] Rashid M.H, "Power Electronics, Circuits, Devices, and Applications", PPH of India Pvt Ltd, New Delhi, $3^{\text {rd }}$ Edition -2013.

[2] Peter Vas "Sensorless Vector and Direct Torque Control", 1998- Oxford University Press.

[3] Cheng T, Dan X, John E. F, Rahman M.F, "Carrier-Based PWM Methods With Common-Mode Voltage Reduction for Five-Phase Coupled Inductor Inverter" IEEE Transactions Industrial Electronics-Jan 2016, vol. 63, no. 1. pp. 526-537, 2015.

[4] Jayaprakash Sabarad, Dr. G.H. Kulkarni, and Sushma Sattigeri, "Dual Three Phase Induction Motor Control Using Five Leg Inverter", IEEE- ICSPACE 2017.

[5] Wei W, Jinghao Z, Ming C, "A Dual-Level Hysteresis Current Control for One Five-Leg VSI to Control Two PMSMs" IEEE Transactions Power Electronics, vol. 32, no. 1, Jan 2017.

[6] M. Jones, S.N. Vukosavic, D. Dujic, P. Wright, E. Levi, "Five-leg inverter PWM technique for reduced switch count two-motor constant power applications", EPA, vol. 2, no. 5, September 2008.

[7] Arkan A. Kadum " PWM control techniques for three phase three level inverter drives",TELKOMNIKA (Telecommunication, Computing, Electronics and Control), vol. 18, no. 1, pp. 519-529, Feb 2020.

[8] Martin J, Drazen D, Emil Levi "A Performance Comparison of PWM Techniques for Five-Leg VSIs Supplying Two-Motor Drives” IEEE, 2008.

[9] Ankit D, Nikhil, S.K.Sinha, and Priyanka S. "A Review on Different PWM Techniques for Five Leg Voltage Source Inverter", IEEE- ICAESM 2012.

[10] Gerardo Escobar Valderrama, Gerardo Vazquez Guzman, Erick I. Pool-Mazún, Panfilo Raymundo M, "A SinglePhase Asymmetrical T-Type Five-Level Transformerless PV Inverter" IEEE Journal of ESTPE vol. 6, no. 1, 2018.

[11] Wei Wang, Jinghao Zhang, Ming Cheng, "A Dual-Level Hysteresis Current Control for One Five-Leg VSI to Control Two PMSMs," IEEE Transaction Power Electronics, vol. 32, no. 1, 2017.

[12] Nicolás T García1 Yeison Alberto G Gomez2 Fredy E Hoyos Velasco on "Parameter estimation of three-phase linear induction motor by a DSP-based electric-drives system", International Journal of Electrical and Computer Engineering (IJECE), vol. 10, no. 1, pp. 626-636, February 2020.

[13] Young-Seol Lim, June-Seok Lee, Kyo-Beum Lee, "Advanced Speed Control for a Five-Leg Inverter Driving a Dual-Induction Motor System", IEEE Transactions on IE, vol. 66, no. 1, 2019.

[14] Yashan Hu, Shoudao Huang, Xuan Wu, Xuefei Li, "Control of Dual Three-Phase Permanent Magnet Synchronous Machine Based on Five-Leg Inverter" IEEE Transactions on Power Electronics, vol. 34, no. 11, 2019.

[15] O.C. Kivanc ; S.B. Ozturk, "Sector determination for SVPWM based four-switch three-phase VSI" IEEE Electronics Letters, vol. 5, no. 5, 2017.

[16] Yong-Chao Liu ; Xinglai Ge ; Qidi Tang ; Bin Gou "Two modified SVPWM algorithms for common-mode voltage reduction in eight-switch three-phase inverters" IEEE Electronics Letters, vol. 53, no. 10, 2017.

[17] Jay K. Pandit, Mohan V. Aware, Ronak V. Nemade, Emil Levi by "Direct Torque Control Scheme for a Six-Phase Induction Motor With Reduced Torque Ripple" IEEE Transactions on Power Electronics, vol. 32, no. 9, 2017.

[18] R. Palanisamy, Th. Ankit Singh, Anamika Ranjan, Jatin Singh "BLDC motor driven electric skateboard using SVPWM", International Journal of Electrical and Computer Engineering (IJECE), vol. 10, no. 1, pp. 711-718, Feb 2020.

[19] Ibrahim Mohd Alsofyani, Yeongsu Bak, Kyo-Beum Lee "Fast Torque Control and Minimized Sector-Flux Droop for Constant Frequency Torque Controller Based DTC of Induction Machines" IEEE Transactions on Power Electronics, vol. 34, no. 12, 2019. 
[20] Gopinathan Vivek, Jayanta Biswas, Meenu D. Nair, Mukti Barai "Simplified double switching SVPWM implementation for three-level VSI" IEEE The Journal of Engineering, vol. 2019, no. 11, 2019.

[21] P. Krishna Reddy,Deepak Ronanki, P. Parthiban "Direct torque and flux control of switched reluctance motor with enhanced torque per ampere ratio and torque ripple reduction" IEEE Journl Electronics letter, vol. 55, no. 8, 2019.

[22] Yuan Ren, Z. Q. Zhu, James E. Green, Yun Li, Shiwu Zhu,Zijian Li "Improved Duty-Ratio-Based Direct Torque Control for Dual Three-Phase Permanent Magnet Synchronous Machine Drives" IEEE Transactions on Industry Applications, vol. 55, no. 6, 2019.

[23] Jayaprakash Sabarad and Dr. G.H. Kulkarni, "Comparative Analysis of SVPWM and SPWM Techniques for Multilevel Inverter", IEEE Conference - ICPACE 2015.

[24] Jayaprakash Sabarad and Dr. G.H. Kulkarni,“ Dual Motor Control using Double Zero Sequence Injection Method in Five Leg Voltage Source Inverter" International Journal of recent technology and Engineering (IJRTE), ISSN: 2277-3878, vol. 8 no. 5, January 2020.

[25] Jinglai $\mathrm{Wu}$, et.al "Efficiency comparison of electric vehicles powertrains with dual motor and single motor input" Elsevier Mechanism and Machine Theory Journal 2018.

\section{BIOGRAPHIES OF AUTHORS}

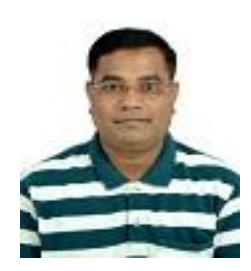

Jayaprakash Sabarad, He obtained Bachelor of Engineering in Electrical and Electronics Engineering in year 2002 from V.T.U. Belagavi, India and M.Tech. in Power and Energy Systems in year 2006 from NITK Surathkal, India. Presently he is Research Scholar in the Department of Electrical Engineering at V.T.U. Belagavi, India. His research interests include Drives Control System and Power Electronics. Email: jpsabarad@gmail.com

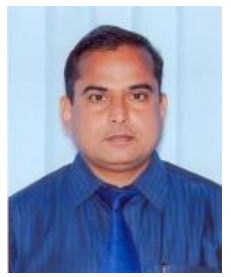

G.H. Kulkarni, He received the Bachelor of Engineering in Electrical Engineering in year 1985 from Karnataka University, Dharwad, India. Master of Technology in year 1992 in the domain of Power Systems from University of Mysore, Karnataka, India and Ph.D. in ANN Applications to Power System from J.N.T.U. Hyderabad, India in 2007. Presently he is working as a HOD of Electrical and Electronics Engineering at Jain College of Engineering Belagavi, India. His areas of interest include ANN application to Power System. Email: eeejceghk@gmail.com 